Jurnal Keperawatan Silampari

Volume 3, Nomor 2, Juni 2020

e-ISSN: 2581-1975

p-ISSN: 2597-7482

DOI: https://doi.org/10.31539/jks.v3i2.1116

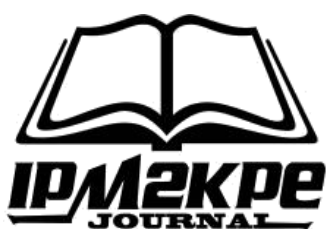

\title{
POSISI SEMI FOWLER TERHADAP RESPIRATORY RATE UNTUK MENURUNKAN SESAK PADA PASIEN TB PARU
}

\author{
Suhatridjas ${ }^{1}$, Isnayati ${ }^{2}$ \\ Akademi Keperawatan Pelni Jakarta ${ }^{1,2}$ \\ suhatridjas@gemail.com ${ }^{1}$
}

\begin{abstract}
ABSTRAK
Tujuan Penelitian untuk mengetahui pengaruh posisi semi fowler terhadap Respiratory Rate pada pasien TB Paru di Ruang rawat inap Rumah Sakit Pelni Jakarta. Metode yang digunakan dalam penelitian ini merupakan penelitian deskriptif dengan pendekatan study kasus. Hasil Penelitian menunjukan bahwa terdapat perubahan respiratory rate dari $21 \mathrm{x} /$ menit menjadi $18 \mathrm{x} /$ menit pada subjek I dan 22x/menit menjadi 19x/menit pada subjek II selama 3 hari perawatan. Simpulan, terdapat perubahan yang signifikan pada kemampuan bernafas pasien sebelum dan sesudah dilakukan intervensi.
\end{abstract}

Kata Kunci : Posisi Semi Fowler, Respiratory Rate, TB Paru

\section{ABSTRACT}

The purpose of this study was to determine the effect of the semi-fowler position on Respiratory Rate in pulmonary TB patients in the Pelni Hospital in Jakarta. The method used in this research is descriptive research with a case study approach. The results showed that there was a change in respiratory rate from $21 x /$ min to $18 x /$ min in the subject I and 22x / min to $19 x$ / min in subject II for three days of treatment. In conclusion, there is a significant change in the patient's breathing ability before and after the intervention.

Keywords: Semi Fowler Position, Respiratory Rate, Lung TB

\section{PENDAHULUAN}

Tuberkulosis adalah suatu penyakit infeksi yang disebabkan oleh mycobacterium tuberculosis yang dapat menular melalui percikan dahak (Kementerian Kesehatan RI, 2017). TB bisa menyerang organ kelenjar getah bening, usus, tulang, otak, dan selaputnya, laring, ginjal bahkan payudara. Tuberkulosis bisa mengenai setiap organ pada tubuh manusia, walaupun sebagian besar tuberkulosis mengenai paru, tapi kejadian ekstra paru atau penyakit TB di luar Paru dilaporkan mencapai 5 hingga $30 \%$. Penyakit ini bila tidak diobati atau pengobatannya tidak tuntas dapat menimbulkan komplikasi berbahaya hingga kematian. Meskipun jumlah kematian akibat Tuberculosis menurun 22\% antara tahun antara tahun 2000-2015, namun tuberculosis masih menepati peringkat ke-10 penyebab kematian tertinggi didunia pada tahun 2016. Oleh sebab itu hingga saat ini. TBC masih menjadi prioritas utama di dunia dan menjadi salah satu tujuan dalam SDGs (Sustainability Development Goals) (Pramasari et al., 2019). 
Penyakit Tuberkulosis (TB) Paru masih merupakan masalah kesehatan bagi masyarakat dunia dan Indonesia. Pemerintah Indonesia telah melakukan upaya pengendalian pada kasus TB paru. Menurut data riset jumlah kasus prevalensi TB Paru berdasarkan diagnosis dokter tidak mengalami pergeseran, yakni sebesar 0,4 persen. Terdapat sejumlah kasus baru TB di Indonesia sebanyak 420.994 kasus pada tahun 2017. Berdasarkan jenis kelamin, jumlah kasus baru TB Paru 2017 pada laki - laki berjumlah 1,4 lebih besar dibandingkan pada perempuan hal ini terjadi kemungkinan karena laki - laki lebih terpapar pada factor risiko TB Paru misalnya merokok dan kurangnya ketidakpatuhan minum obat. Suvei ini menemukan bahwa dari seluruh partisipan laki - laki yang merokok sebanyak 68,5\% dan hanya 3,7\% partisipan perempuan yang merokok (Kementerian Kesehatan RI, 2018).

Penyakit TBC paru yang disebabkan terjadi ketika daya tahan tubuh menurun. Dalam perspektif epidemiologi yang melihat kejadian penyakit sebagai hasil interaksi antar tiga komponen pejamu (host), penyebab (agent), dan lingkungan (environment) dapat ditelaah faktor risiko dari simpul-simpul tersebut. Pada sisi pejamu, kerentanan terhadap infeksi Mycobacterium tuberculosis sangat dipengaruhi oleh daya tahan tubuh seseorang pada saat itu. Pengidap HIV AIDS atau orang dengan status gizi yang buruk lebih mudah untuk terinfeksi dan terjangkit TBC (Kementerian Kesehatan RI, 2018).

Gejala penyakit TBC berupa gejala umum dan khusus, keadaan ini di sesuaikan dengan organ tubuh yang terserang oleh penyakit. Tanda secara klinis tidak terlalu khas terutama pasien pasien yang baru awal menderita TB. Adapun gejala umum meliputi batuk-batuk selama 3 minggu, biasanya berupa batuk darah disertai demam dan keringat dingin pada malam hari, bisa disertai demam influenza yang sifatnya hilang timbul, penurunan nafsu makan yang akan menyebabkan berat badan turun, sedangkan gejala khususnya tergantung pada bagian mana tubuh terkena, pada sebagian penderita TB mengalami gangguan pada jalan napas, bila terjadi sumbatan pada daerah bronkus maka akan menyebabkan penekanan pada kelenjar betah bening, dan menimbulkan suara mengi, suara napas akan melemah dan dada menjadi sesak serta kesulitan bernafas (Namuwali et al., 2016; Santana, Muntamah, 2019).

Menurut Kementerian Kesehatan RI (2018) gejala umum pada pasien TB paru ini adalah batuk selama 3-4 minggu atau lebih, batuk dapat diikuti dengan gejala tambahan yaitu dahak bercampur darah, batuk darah, sesak nafas, badan lemas dan nafsu makan menurun, berat badan menurun, malaise, berkeringat pada malam hari tanpa kegiatan fisik, dan demam meriang lebih dari satu bulan.

Upaya mengatasi masalah tuberculosis di Indonesia TOSS TBC (Temukan Obati Sampai Sembuh) Adalah gerakan untuk menemukan pasien sebanyak mungkin dan mengobati sampai sembuh sehingga rantai penularan di masyarakat bisa dihentikan. Gerakan TOSS TBC sebagai upaya pencegahan dan pengendalian TBC (Kementerian Kesehatan RI, 2018; Gloria et al.,2019).

Salah satu terapi non farmakologis yang bisa dilakukan untuk menurunkan sesak napas pada pasien TB paru adalah dengan mengatur posisi pasien dengan semi fowler. Dengan menggunakan posisi semi fowler yaitu menggunakan gaya gravitasi untuk membantu pengembangan paru dan mengurangi tekanan dari visceral-visceral abdomen pada diafragma sehingga diafragma dapat terangkat dan paru akan berkembang secara maksimal dan volume tidal paru akan terpenuhi. Dengan terpenuhinya volume tidal paru maka sesak nafas dan penurunan saturasi oksigen pasien akan berkurang. Posisi semi fowler biasanya diberikan kepada pasien dengan sesak nafas yang beresiko 
mengalami penurunan saturasi oksigen, seperti pasien TB paru, asma, PPOK dan pasien kardiopulmonari dengan derajat kemiringan 30-45 (Wijayati et al., 2019).

Penelitian yang telah dilakukan oleh Aini et al., (2016) ditemukan bahwa dari 22 responden sebagian besar responden setelah dilakukan pemberian posisi semi fowler, responden dengan pernafasan normal 16 - 24x/menit sebanyak 15 orang $(68,2 \%)$, pernafasan bradipnea 2 orang, responden dengan takhipnea $>23 x /$ menit sebanyak 5 orang.

Sama halnya dengan penelitian yang telah dilakukan oleh Zahroh, Susanto (2017) menunjukan bahwa jumlah hampir seliruh penderita mengalami penurunan sesak nafas yaitu 15 orang $(93,75 \%)$, sedangkan sebagian kecil pasien tidak mengalami penurunan sesak nafas yaitu 1 orang $(6,25 \%)$. Untuk variable posisi semi fowler diuji dengan uji paired $t$ - test didapatkan signifikansi sebesar $p=0.000(p<0,005)$ maka H0 ditolak artinya terdapat penurunan sesak nafas sebelum dan sesudah diberikan posisi semi fowler .

Berdasarkan studi awal pendahuluan yang dilakukan peneliti tahun 2019 di Rumah Sakit Pelni Jakarta Ruangan penyakit dalam terdapat 4 pasien yang menderita penyakit TB paru di ruang Flamboyan, peneliti mendapatkan hasil wawancara 1 pasien mengatakan ketika sesak pasien di berikan posisi semi fowler pasien merasa sesak berkurang, dan 3 pasien ketika sesak tidak ingin dilakukan tindakan posisi semi fowler, pasien beranggapan tidak dapat mengurangi sesak yang di alami pasien hanya berbaring dan di bantu dengan O2 kanul. Dari hasil observasi tersebut yang di lakukan di ruang Flamboyan pasien masih belum mengetahui secara benar tentang mengurangi sesak dengan pemberian posisi semi fowler pada pasien TBC. Penelitian bisa .Hasil penelitian dapat di jadikan tambahan informasi bagi penelitian di bidang keperawatan, khususnya penelitian mengenai analisis intervensi posisi semi fowler terhadaprespiratory rate untuk menurunkan sesak Pada pasien TB elanjutnya dapat dilakukan dengan menggunakan dua metode sekaligus kuanlitatif.

Penelitian tentang TB Paru telah banyak dilakukan di berbagai belahan dunia namun penyakit ini masih menjadi salah satu penyakit menular yang di takuti, masih ada pasien yang meningal karna tidak tidak paham tentang memahami metode terbaru untuk menurunkan sesak napas agar pasien tidak measa cemas, cemas yang berlebihan dapat mempengaruhi pola pikir pasien yang mengidap penyakit TB oleh karna itu peneliti lebih menekankan kelebihan dari peneltian ini di ambil dari psikologis seorang pasien yang mengidap penyakit TB Paru bisa menurunkan sesak napas pasien dengan cara mengatur posisi pasien.

\section{METODE PENELITIAN}

Desain penelitian deskriptif yang dipilih untuk penelitian yang akan dilaksanakan dengan pendekatan study kasus yaitu merupakan metode ilmiah yang dimulai dari mengumpulkan data dan menarik kesimpulan data. Pada penelitian ini peneliti menhgukur jumlah perenafasan pada pasien TB paru sebelum dilakukan intervensi pemberian posisi semi fowler dan sesudah dilakukan posisi semi fowler. Desain rancangan penelitian yang digunakan yaitu pre dan post test group design jumlah frekuensi pernafasa sesudah diberikan posisi semi fowler terhadap perubahan sesak nafas pada penderita TB paru diruang rawat inap Rumah Sakit Pelni Jakarta tahun 2018. 
Gambaran skema penelitian yang dilakukan yaitu : A1 --- .B.....A2

A1 = Pengukuran frekuensi pernafasan sebelum dilakukan intervensi pemberian posisi semi fowler

$\mathrm{B}=$ Intervensi posisi semi fowler

A2 =Pengukuran frekuensi pernafasan setelah dilakukan intervensi osisi semi fowler

Kriteria inklusi sampel dalam penelitian ini adalah (1) Pasien yang sedang dirawat di Rumah Sakit Pelni, (2) Pasien yang bersedia menjadi responden dan mengikuti penelitian (3) Pasien TB paru yang mengalamisesak nafas,(4) pasien yang kesadaran nya baik.(5) Pasien TB paru berjenis kelamin laki2 pasien yang bisa diajak kerjasama. Kriteria eksklusi sample dalam penelitian ini : (1) Psien TB paru yang mengalami komplikasi (2) pasien yang dengan gangguan psikologis (3) penurnan kesadaran

Instrumen penelitian adalah suatu alat yang digunakan untuk mengukur fenomena alam maupun sekitar yang diamatidengan menggunakan instrument yang dignakan dalam penelitian ini yaitu lembar inform consent, format observasi ( Performent assessment dan pengukuran frekuensi pernafasan ), lembar kuisioner serta jam tangan yang menggunakan second (detik) sebagai alat untuk menghitung frekuensi pernafasan per menitnya.

Kegiatan penelitian ini dilakukan selama 3 hari setiap harinya dua kali pertemuan, catatan kegiatan dan kemajuan frekuensi pernafasan dari masing- masing subyek diuraikan dalam bentuk narasi, namun proses lengkapnya disajikan pada lampiran. Sebelum peneliti mengadakan penelitian ini mencari klien yang sesuai dengan kriteria inklusi yaitu pasien yang sedang dirawat di Rumah Sakit Pelni. Pasien yang bersedia menjadi responden dan mengikuti penelitian ini sampai selesai, pasien TB paru yang mengalami sesak nafas dan berjenis kelamin laki- laki. Setelah menemukan pasien yang sesuai dengan kriteria inklusi tsb, pertama kali yang dilakukan adalah memperkenalkan diri, melakukan wawancara awal tentang keluhan yang dirasakan klien saat ini dan melakukan pemeriksaan fisik sambil memperhatikan keadaan pasien yang sesuai dengan kriteri inklusi yang ditetapkan. Setelah itu peneliti menjelaskan maksud dan tujuan dari penegaturan posisi semi fowler.

Selanjutnya meminta pasien menanadatangani lembaran formulir persetujuan (inform consent). Setelah mendapatkan persetujuan peneliti langsung melakukan intervensi yang terlebih dahulu menghitung frekuensi pernafasan yang dilanjutkan dengan melakukan intervensi memberikan posisi semi fowler sesuai dengan lembaran formulir performance intervensi posisi semi fowler, kemudian menanyakan kepada pasien apakah pasien merasa nyaman, apakah ada perubahan sesak yang dirasakan pasien.terutama apakah pasien merasa sesak dan dada terasa berat, setelah nya menghitung kembali frekuensi pernafasan.

\section{HASIL PENELITIAN}

Tabel. 1

Frekuensi Pernapasan Sebelum dan Sesudah Intervensi

\begin{tabular}{|c|c|c|c|c|c|}
\hline \multirow[t]{2}{*}{ Pertemuan } & \multirow[t]{2}{*}{ Tanggal } & \multirow[t]{2}{*}{ Pukul } & \multirow[t]{2}{*}{ Aspek } & \multicolumn{2}{|c|}{ Posisi semi fowler } \\
\hline & & & & Pre & Post \\
\hline \multirow{4}{*}{1.} & \multirow{4}{*}{$\begin{array}{c}7 \text { agustus } \\
2019\end{array}$} & 12.45 & Respiratory rate & $21 \mathrm{x} / \mathrm{menit}$ & 20x/menit \\
\hline & & & Saturasi Oksigen & $98 \%$ & $99 \%$ \\
\hline & & 19.00 & Respiratory rate & $20 x /$ menit & $19 \mathrm{x} /$ menit \\
\hline & & & Saturasi oksigen & $99 \%$ & $99 \%$ \\
\hline
\end{tabular}




\begin{tabular}{|c|c|c|c|c|c|}
\hline & & 10.00 & Respiratory rate & 20x/menit & 19x/menit \\
\hline \multirow{3}{*}{2.} & 8 agustus & & Saturasi oksigen & $98 \%$ & $100 \%$ \\
\hline & 2019 & 19.00 & Respiratory Rate & $21 \mathrm{x} /$ menit & $19 \mathrm{x} /$ menit \\
\hline & & & Saturasi Oksigen & $97 \%$ & $99 \%$ \\
\hline \multirow{4}{*}{3.} & & 10.00 & Respiratory Rate & 20x/menit & 19x/menit \\
\hline & 9 agustus & & Saturasi Oksigen & $98 \%$ & $100 \%$ \\
\hline & 2019 & 19.00 & Respiratory Rate & 20x/menit & $18 \mathrm{x} /$ menit \\
\hline & & & Saturasi Okaigen & $97 \%$ & $100 \%$ \\
\hline
\end{tabular}

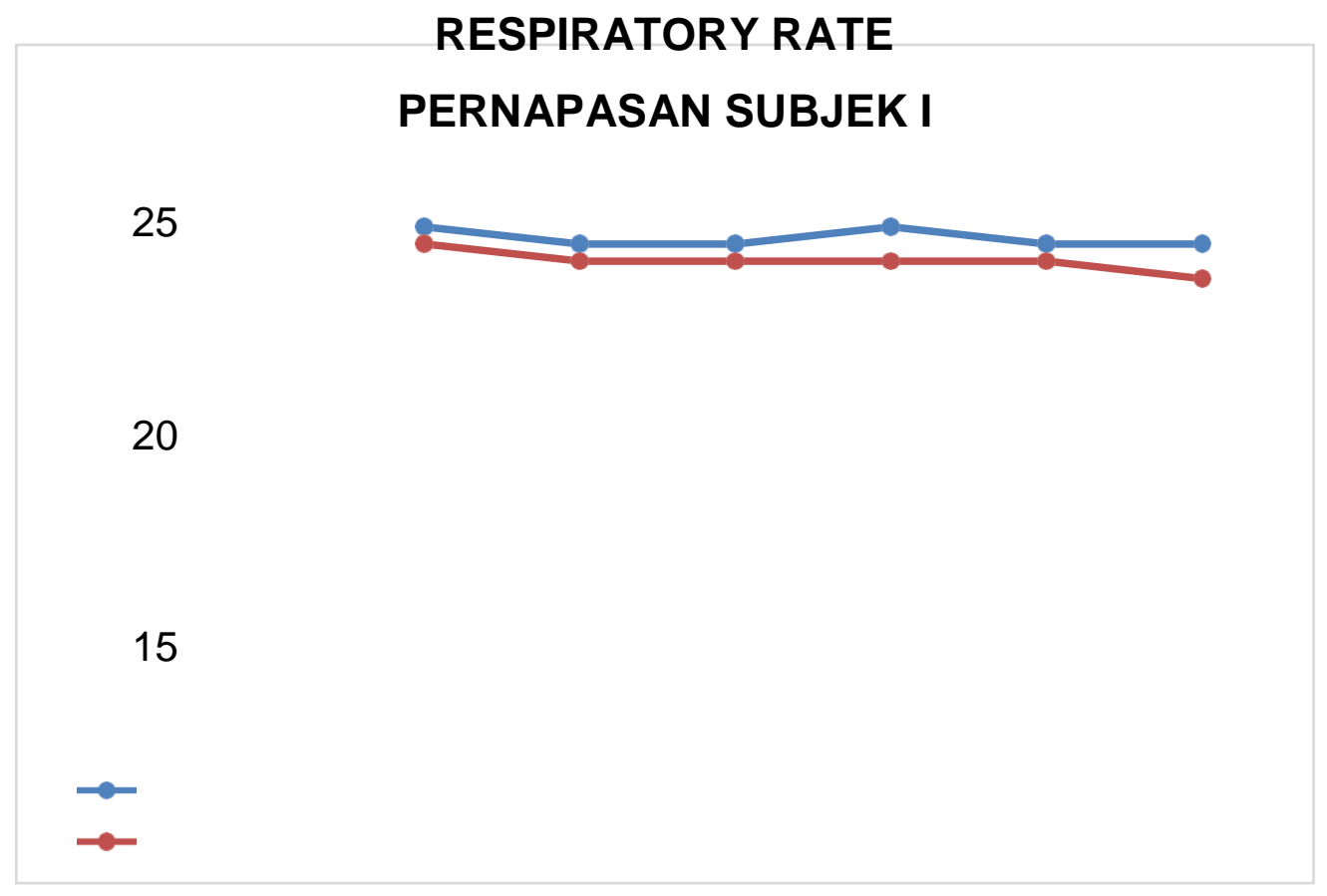

Grafik. 1

Respiratory Rate Pernapasan Subjek I

Subjek I berjenis kelamin laki - laki, berumur 24 tahun status pendidkan lulusan SMA, bekerja sebagai pegawai POM bensin, status belum menikah. Saat dilakukan wawancara didapatkan hasil yang menunjukan bahwa subjek mengeluh sesak napas, nyeri dada dan batuk sudah satu bulan. TTV TD: 110/60 mmHg, $\mathrm{N}$ : $65 \mathrm{x} / \mathrm{menit}$, RR: 21x/menit, suhu: $36,7^{\circ} \mathrm{C}$ SPO2: $98 \%$, suara napas ronkhi positif, kedalaman napas dangkal, sputum sulit dikeluarkan. Saat dilakukan wawancara didapatkan hasil yang menunjukan bahwa subjek mengeluh sesak napas, nyeri dada dan batuk sudah hampir 2 bulan. Dengan hasil TTV TD :120/80MMhg, S:36,3OC, N:87x/mnt, RR: 22x/mnt, SPO2: 97\%, suara napas ronkhi, kedalaman napas pendek.

Kondisi subyek setelah dilakukan intervensi posisi semi fowler, evaluasi secara keseluruhan pada sebelum dilakukan intervensi pasien mengeluh sesak napas, nyeri dada, batuk, RR 21x/mnt, SPO2: 98\%. Setelah dilakukan ubah posisi semi fowler, pasien mengatakan nyaman, sesak sudah tidak ada RR: 18x/mnt, SPO2 100\%. Dokter penangung jawab pasien memperbolehkan rawat jalan, klien rawat jalan sabtu 9 Agustus 2019 pukul 09.00 WIB. 
Tabel. 2

Frekuensi Pernapasan Sebelum dan Sesudah Intervensi

\begin{tabular}{|c|c|c|c|c|c|}
\hline \multirow[b]{2}{*}{ Pertemuan } & \multirow[b]{2}{*}{ Tanggal } & \multirow[b]{2}{*}{ Pukul } & \multirow[b]{2}{*}{ Aspek } & \multicolumn{2}{|c|}{ Posisi semi fowler } \\
\hline & & & & Pre & Post \\
\hline \multirow{3}{*}{1.} & \multirow{3}{*}{$\begin{array}{l}8 \text { agustus } \\
2019\end{array}$} & 10.00 & Respiratory rate & $22 x /$ menit & 19x/menit \\
\hline & & & Saturasi Oksigen & $97 \%$ & $99 \%$ \\
\hline & & 19.00 & $\begin{array}{l}\text { Respiratory rate } \\
\text { Saturasi oksigen }\end{array}$ & $\begin{array}{l}21 \times / \text { menit } \\
97 \%\end{array}$ & $\begin{array}{l}20 \mathrm{x} / \text { menit } \\
99 \%\end{array}$ \\
\hline \multirow{3}{*}{2.} & 9 agustus & 10.15 & $\begin{array}{l}\text { Respiratory rate } \\
\text { Saturasi oksigen }\end{array}$ & $\begin{array}{l}21 x / \text { menit } \\
96 \%\end{array}$ & $\begin{array}{l}\text { 19x/menit } \\
99 \%\end{array}$ \\
\hline & 2019 & 19.00 & Respiratory Rate & $22 x /$ menit & 19x/menit \\
\hline & $\begin{array}{l}\text { 10agustus } \\
2019\end{array}$ & 10.00 & $\begin{array}{l}\text { Saturasi Oksigen } \\
\text { Respiratory Rate } \\
\text { Saturasi Oksigen }\end{array}$ & $\begin{array}{l}97 \% \\
21 \times / \text { menit } \\
99 \%\end{array}$ & $\begin{array}{l}100 \% \\
19 x / m e n i t \\
99 \%\end{array}$ \\
\hline 3. & & 19.00 & $\begin{array}{l}\text { Respiratory Rate } \\
\text { Saturasi Okaigen }\end{array}$ & $\begin{array}{l}\text { 20x/menit } \\
98 \%\end{array}$ & $\begin{array}{l}\text { 19x/menit } \\
97 \%\end{array}$ \\
\hline
\end{tabular}

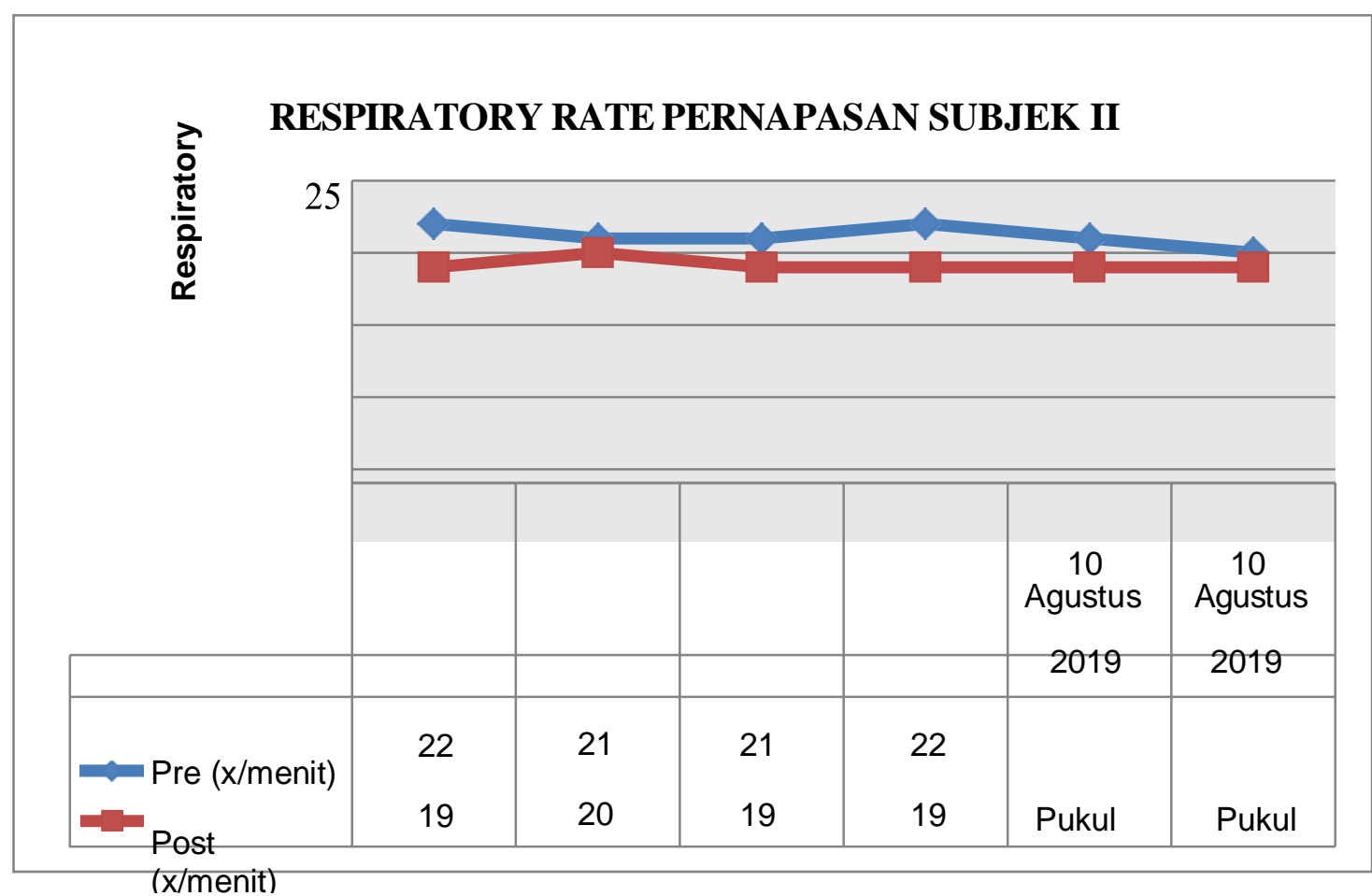

Grafik. 2

Respiratory Rate Pernapasan Subjek II

Subjek II berjenis kelamin laki- laki berusia 47 tahun, status pendidkan lulusan SMA,bekerja sebagai karyawan, status sudah menikah, sebelum dilakukan intervensi dari hasi pengamatan keadaan umum sedang, kesadaran kompos mentis, nafas sesak, saat dilakukan wawancara mengeluh nafas terasa sesak dada nyeri saat bernapas dan batuk sudah 2 bulan. Tidak tahu penyebab TB paru dan menduga penyebab TB paru karena merokok. Setelah dilakukan pengkajian, subjek II sesuai dengan kriteria inklusi peneliti merupakan pasien TB paru yang sedang dirawat di Rumah Sakit Pelni Jakarta, sedang mengalami sesak napas, berjenis kelamin laki - laki bersedia menjadi responden 
dan mengikuti prosedur penelitian sampai dengan tahap akhir, mampu diajak berkomunikasi dan mengikuti pengaraha, dengan hasil TTV TD: 120/80 mmHhg, $\mathrm{S}: 36,3 \mathrm{OC}, \mathrm{N}: 87 \mathrm{x} / \mathrm{mnt}, \mathrm{RR}: 22 \mathrm{x} / \mathrm{mnt}, \mathrm{SPO} 2: 97 \%$, suara napas ronkhi, kedalaman napas dangkal.

Pemberian posisi semi fowler yang diberikan pada klien mengalami penurunan pada tanggal 7 agustus 2019 pukul 12.45 respiratory rate menunjukan angka 20x/menit, pada pukul 19.00 mengalami penurunan yaitu angka 19x/menit. Dilakukan intervensi pada hari berikutnya di tanggal 8 agustus 2019 pukul10.00 respiratory rate mengalami penurunan 19x/menit dan pada pukul 19.00 mengalami penurunan menjadi 19x/menit. Pada hari terakhir dilakukan proses intervensi, respiatory rate klien pada tanggal 9 agustus 2019 pada pukul 10.00 menjadi 19x/menit dan pada pukul 19.00 menjadi $18 \mathrm{x} / \mathrm{menit}$

\section{PEMBAHASAN}

Kondisi subyek I setelah dilakukan intervensi posisi semi fowler, evaluasi secara keseluruhan pada sebelum dilakukan intervensi pasien mengeluh sesak napas, nyeri dada, batuk, RR 21x/mnt, SPO2: 98\%. Setelah dilakukan ubah posisi semi fowler, pasien mengatakan nyaman, sesak sudah tidak ada RR: 18x/mnt, SPO2 100\%. Berdasarkan hasil penelitian yang dilakukan, Subjek I berusia 24 tahun dan Subjek II berusia 47 tahun. Ini sesuai dengan penelitan depkes 2009 bahwa sekitar 75\% responden memiliki karakteritik usia produkif secara ekonomi (15 - 50 tahun) lebih rentan terkena TB di karenakan di usia tersebut orang yang melakukan kegiatan aktif tanpa menjaga kesehatan beresiko lebih mudah terserang TB

Karakteristik subjek penelitian tidak memiliki perbedaan dimana kedua subjek berjenis kelamin laki - laki dan faktor pencetus yang menjadikan penyebab TB paru adalah sering merokok. Hal ini sesuai dengan hasil penelitian Riskesdas 2018 yang menunjukkan bahwa kasus TB paru pada laki - laki 1,4 kali lebih besar dibandingkan perempuan, terdapat 245.298 kasus berdasarkan jenis kelamin laki - laki dan 175.696 pada perempuan, hal ini terjadi kemungkinan karena laki - laki lebih terpapar pada faktor resiko TBC misalnya merokok dan kurangnya kepatuhan minum obat.

Hasil penelitian tentang analisis intervensi posisi semi fowler terhadap respiratory rate untuk menurunkan sesak nafas pada pasien TB paru di Rumah Sakit Pelni Jakarta yang dilakukan selama 3 hari dalam 2x pertemuan setiap harinya, subjek I dan Subjek II mengalami penurunan sesak nafas dengan angka respiratory rate normal $12-20 \mathrm{x} / \mathrm{mnt}$ setelah dilakukan intervensi posisi semi fowler.

Salah satu terapi non farmakologis yang bisa dilakukan untuk menurunkan sesak napas pada pasien TB paru adalah dengan mengatur posisi pasien dengan semi fowler. Penelitian yang telah dilakukan oleh Aini et al., (2016) ditemukan bahwa dari 22 responden sebagian besar responden setelah dilakukan pemberian posisi semi fowler, responden dengan pernafasan normal 16 - 24x/menit sebanyak 15 orang $(68,2 \%)$, pernafasan bradipnea 2 orang, responden dengan takhipnea $>23 \mathrm{x} /$ menit sebanyak 5 orang.

Sama halnya dengan penelitian yang telah dilakukan oleh Zahroh, Susanto (2017) menunjukan bahwa hampir seluruh penderita mengalami penurunan sesak nafas yaitu 15 orang $(93,75 \%)$, sedangkan sebagian kecil pasien tidak mengalami penurunan sesak nafas yaitu 1 orang $(6,25 \%)$. Untuk variable posisi semi fowler diuji dengan uji paired $t$ - test didapatkan signifikansi sebesar $p=0.000(p<0,005)$, terdapat penurunan sesak nafas sebelum dan sesudah diberikan posisi semi fowler . 
Pemberian posisi semi fowler pada pasien TB paru telah dilakukan sebagai salah satu cara untuk membantu mengurangi sesak napas. Keefektifan dari tindakan tersebut dapat dilihat dari respiratory rate yang menunjukkan angka normal yaitu 16-24x per menit pada usia dewasa. Pelaksanaan asuhan keperawatan dalam pemberian posisi semi fowler itu sendiri dengan menggunakan tempat tidur dan fasilitas bantal yang cukup untu menyangga daerah punggung, sehingga dapat memberi kenyamanan saat tidur dan dapat mengurangi kondisi sesak nafas pada pasien asma saat terjadi serangan (Aini et al., 2016).

Dengan menggunakan posisi semi fowler yaitu menggunakan gaya gravitasi untuk membantu pengembangan paru dan mengurangi tekanan dari visceral-visceral abdomen pada diafragma sehingga diafragma dapat terangkat dan paru akan berkembang secara maksimal dan volume tidal paru akan terpenuhi. Dengan terpenuhinya volume tidal paru maka sesak nafas dan penurunan saturasi oksigen pasien akan berkurang. Posisi semi fowler biasanya diberikan kepada pasien dengan sesak nafas yang beresiko mengalami penurunan saturasi oksigen, seperti pasien TB paru, asma, PPOK dan pasien kardiopulmonari dengan derajat kemiringan 30-45 (Wijayati et al., 2019).

Penelitian yang dilakukan oleh Yuliana et al., (2017) menyatakan bahwa ada pengaruh yang signifikan antara posisi semi fowler $30^{\circ}$ dan $45^{\circ}$ terhadap keefektifan pola napas pada pasienTB Paru di Ruang Anggrek RS paru Dungus. Sejalan juga dengan penelitian yang dilakukan Wijayati et al., (2019) ada pengaruh posisi tidur semi fowler $45^{\circ}$ terhadap kenaikan nilai saturasi oksigen pada pasien gagal jantung kongestif. Penelitian ini merekomendasikan agar pasien gagal jantung kongestif dengan penurunan saturasi oksigen diberikan posisi tidur semi fowler $45^{\circ}$.

Penelitian yang dilakukan Desyarti tahun 2018 menunjukkan bahwa terdapat pengaruh perubahan respirasi atau pola pernafasan pada pasien efusi pleura setelah dilakukan tindakan semi fowler (Desyarti et al., 2018).

Pada hasil grafik respiratory rate di atas, saat proses intervensi pemberian posisi semi fowler yang diberikan pada klien mengalami penurunan pada tanggal 8 agustus 2019 pukul 10.05 respiratory rate menunjukan angka 19x/menit, pada pukul 19.00 mengalami penurunan yaitu angka 20x/menit. Dilakukan intervensi pada hari berikutnya di tanggal 9 agustus 2019 pukul 10.15 respiratory rate mengalami penurunan 19x/menit dan pada pukul 19.00 mengalami penurunan menjadi 19x/menit. Pada hari terakhir dilakukan proses intervensi, respiatory rate klien pada tanggal 10 agustus 2019 pada pukul 10.00 menjadi 19x/menit dan pada pukul 19.00 menjadi $19 \mathrm{x} /$ menit.

\section{SIMPULAN}

Respiratory rate sebelum dan sesudah dilakukan posisi semi fowler terjadi perubahan. Pada kedua subjek penelitian terdapat perubahan respiratory Rate sebelum dan sesudah diberikan intervensi posisi semi fowler. Penurunan sesak napas tersebut didukung juga dengan sikap pasien yang kooperaktif, patuh saat diberikan posisi semi fowler sehingga pasien dapat bernafas.

Menurunkan sesak nafas tidak hanya dengan pemberian obat-obatan saja, ada intervensi non farmakoterapi seperti posisi semi fowler pada pasien TB paru telah dilakukan sebagai cara membantu mengurangi sesak napas. Posisi semi fowler dimana kepala dan tubuh dinaikkan $45^{\circ}$ membuat oksigen didalam paru-paru semakin meningkat sehingga memperingan kesukaran napas. 


\section{SARAN}

\section{Bagi Institusi Pendidikan}

Diharapkan penelitian ini dapat menambah referensi tentang upaya penurunan sesak nafas menggunakan posisi semi fowler untuk mendukung peneliti-peneliti berikutnya.

\section{Bagi Perawat}

Diharapkan penelitian ini sebagai masukan bagi profesi perawat agar meningkatkan pelayanan kesehatan, khususnya alternatif non farmakologi denganposisi semi fowler untuk menurunkan sesak nafas. Diharapkan

\section{Penelitian Selanjutnya}

Menggunakan penelitian ini sebagai referensi sehingga dapat mengembangkan konsep atau melakukan penelitian tentang menurunkan sesak nafas menggunakan intervensi posisi semi fowler dengan cara yang lebih mudah dan jumlah sampel yang lebih banyak.

\section{DAFTAR PUSTAKA}

Aini, D. N., Arifianto, A., \& Sapitri, S. (2016). Pengaruh Pemberian Posisi Semi Fowler terhadap Respiratory Rate Pasien Tiberkulosis Paru di Ruang Flamboyan RSUD Soewondo Kendal. Jurnal Ners Widya Husada, 3(2), 1-9. http://stikeswh.ac.id:8082/journal/index.php/jners/article/view/174/165

Desyarti, N., Putra, A., \& Ageng, M. (2018). Analisa Tindakan Posisi Semi Fowler dengan Masalah Keperawatan Ketidakefektifan Pola Nafas pada Pasien Efusi Pleura di Ruang IGD Rumah Sakit Prod. DR. Margono Soekarjo Purwokerto. Sekolah Tinggi Ilmu Kesehatan Muhammadiyah Gombong

Kementerian Kesehatan RI. (2017). Pedoman Nasional Penanggulangan Tuberkulosis

Kementerian Kesehatan RI. (2018). Infodatin Tuberkulosis. Usat Data Dan Informasi Kementerian Kesehatan $R I$, 1. https://www.depkes.go.id/article/view/18030500005/waspadai-peningkatanpenyakit-menular.html\%0Ahttp://www.depkes.go.id/article/view/17070700004/ program-indonesia-sehat-dengan-pendekatan-keluarga.html

Namuwali, D., Mendrofa, F. A., \& Dwidiyanti, M. (2016). Teknik Relaksasi Meningkatkan Kontrol Emosi pada Penderita dengan Penyakit Kronis. Jurnal Penelitian Kesehatan Suara Forikes, VII(3), 156-160

Pramasari, D., Pramono, J. S., \& Frana, A. (2019). Asuhan Keperawatan pada Pasien Tuberculosis Paru di Ruang Seruni Rumah Sakit Umum Daerah Abdul Wahab Sjahranie Samarinda. Politeknik Kesehatan Kementerian Kesehatan Samarinda

Santana, A. C., \& Muntamah, U. (2019). Pengelolaan Ketidakefektifan Bersihan Jalan Napas pada Tn. M dengan Tuberculosis Paru di Ruang Dahlia RSUD Ungaran. Universitas Ngudi Waluyo

Wijayati, S., Ningrum, D. H., \& Putrono, P. (2019). Pengaruh Posisi Tidur Semi Fowler $45{ }^{\circ}$ terhadap Kenaikan Nilai Saturasi Oksigen pada Pasien Gagal Jantung Kongestif di RSUD Loekmono Hadi Kudus. Medica Hospitalia; Journal of Clinical Medicine, 6(1), 13-19

Yuliana, S. E., Putri, M. A., \& Bachrun, E. (2017). Pengaruh Pemberian Posisi Semi Fowler 300 dan 450 terhadap Keefektifan Pola Napas pada Pasien TB Paru di Ruang Anggrek RS Paru Dungus. STIKES Bhakti Husada Mulia Madiun 
Zahroh, R., \& Susanto, R. S. (2017). Efektifitas Posisi Semi Fowler dan Posisi Orthopnea terhadap Penurunan Sesak Napas Pasien TB Paru. Jouenal of Ners Community, $8(1)$,

$37-44$. http://journal.unigres.ac.id/index.php/JNC/article/view/284 